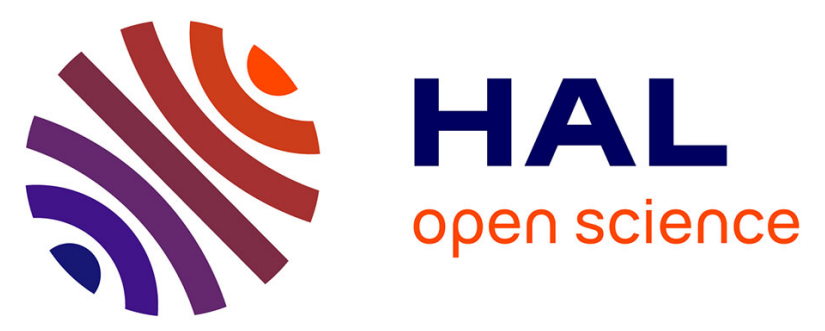

\title{
Switchable Alkene Epoxidation/Oxidative Cleavage with H2O2/NaHCO3: Efficient Heterogeneous Catalysis Derived from Biosourced Eco-Mn
}

Vincent Escande, Eddy Petit, Laetitia Garoux, Clotilde Boulanger, Claude Grison

\section{To cite this version:}

Vincent Escande, Eddy Petit, Laetitia Garoux, Clotilde Boulanger, Claude Grison. Switchable Alkene Epoxidation/Oxidative Cleavage with $\mathrm{H} 2 \mathrm{O} 2 / \mathrm{NaHCO} 3$ : Efficient Heterogeneous Catalysis Derived from Biosourced Eco-Mn. ACS Sustainable Chemistry \& Engineering, 2015, 3 (11), pp.2704-2715. 10.1021/acssuschemeng.5b00561 . hal-01297872

\section{HAL Id: hal-01297872 \\ https://hal.science/hal-01297872}

Submitted on 11 Mar 2021

HAL is a multi-disciplinary open access archive for the deposit and dissemination of scientific research documents, whether they are published or not. The documents may come from teaching and research institutions in France or abroad, or from public or private research centers.
L'archive ouverte pluridisciplinaire HAL, est destinée au dépôt et à la diffusion de documents scientifiques de niveau recherche, publiés ou non, émanant des établissements d'enseignement et de recherche français ou étrangers, des laboratoires publics ou privés. 


\title{
Switchable Alkene Epoxidation/Oxidative Cleavage with $\mathrm{H}_{2} \mathrm{O}_{2} / \mathrm{NaHCO}_{3}$ : Efficient Heterogeneous Catalysis Derived from Biosourced Eco-Mn
}

\author{
Vincent Escande, ${ }^{\dagger}$ Eddy Petit, ${ }^{\ddagger}$ Laetitia Garoux, ${ }^{\S}$ Clotilde Boulanger, ${ }^{\S}$ and Claude Grison ${ }^{* \dagger}$ \\ ${ }^{\dagger}$ ChimEco, FRE 3673 CNRS-UM2-Stratoz, Bio-inspired Chemistry and Ecological Innovations, Cap Alpha - Avenue de l’Europe, \\ 34830 Clapiers (Montpellier), France \\ ${ }^{\ddagger}$ European Membranes Institute, UMR 5635, CC 047, Place Eugène Bataillon, 34095 Montpellier, France \\ § Jean Lamour Institute, UMR 7198, Lorraine University-CNRS, 1 boulevard Arago, CP87811, 57078 Metz, France
}

\begin{abstract}
A novel Mn-derived catalyst was prepared starting from the biomass of Mn-hyperaccumulating plants growing on metal-rich soils. Recovery of this biomass as valueadded "ecocatalyst" provides incentives for the development of phytoextraction programs on soils degraded by mining activities. Characterization of the resulting plant-based catalyst Eco-Mn by inductively coupled plasma mass spectrometry (ICP-MS), X-ray diffraction (XRD), X-ray fluorescence spectrometry (XRF), and X-ray photoelectron spectroscopy (XPS) demonstrated the presence of unusual polymetallic complexes of $\mathrm{Mn}(\mathrm{II})$ in the catalyst, along with $\mathrm{Fe}(\mathrm{III})$. Incorporation of these species into montmorillonite $\mathrm{K} 10$ as solid support provided a supported Eco-Mn catalyst, whose properties were investigated for alkene epoxidation with $\mathrm{H}_{2} \mathrm{O}_{2}\left(30\right.$ wt \%)/ $\mathrm{NaHCO}_{3}(0.2 \mathrm{M})$ as a green

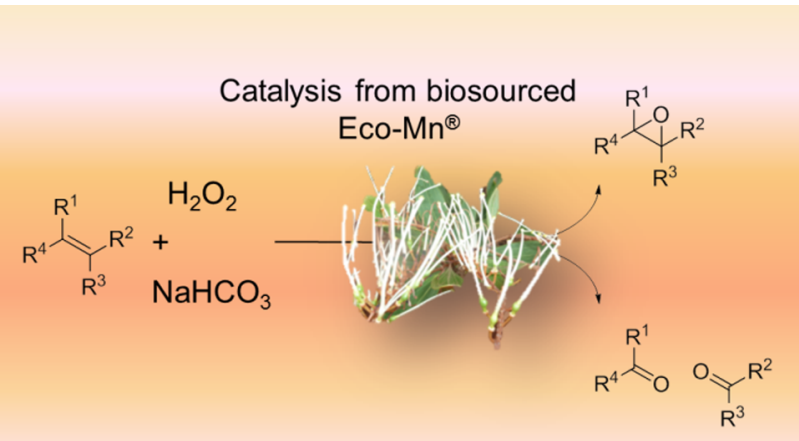
terminal-oxidizing reagent. The supported Eco-Mn catalyst demonstrated a high efficiency for styrene epoxidation, with only $0.31 \mathrm{~mol} \% \mathrm{Mn}$, a much lower content of Mn than in previously described Mn-derived heterogeneous catalysts. Although Fe was also present in the supported Eco-Mn catalyst, comparison experiments showed that Fe had only a limited role in the catalysis. The water content in the reaction medium had a beneficial effect, increasing the reaction efficiency. The supported Eco-Mn catalyst was recycled four times without any loss of activity. Comparison of its properties to those of heterogeneous catalysts made by incorporation of commercial $\mathrm{MnCl}_{2} \cdot 4 \mathrm{H}_{2} \mathrm{O}$ and $\mathrm{FeCl}_{3} \cdot 6 \mathrm{H}_{2} \mathrm{O}$ highlighted the superior catalytic activity of polymetallic species present in the biosourced catalyst. The substrate scope of the method was extended to various alkenes, including bulky natural products which were epoxidized with high yields (up to 99\%), sometimes much higher than those obtained with already described Mn-derived heterogeneous catalysts. Finally, by simple adjustments of reaction conditions, the method allowed controlled access to aldehydes by oxidative cleavage of various styrene-derived substrates (up to 93\% yield). The method thus constitutes a valuable alternative not only to classical epoxidation reagents but also to oxidative cleavage of styrene-derived molecules, which usually involves toxic and hazardous reagents.
\end{abstract}

KEYWORDS: Alkene epoxidation, Alkene oxidative cleavage, Heterogeneous catalyst, Polymetallic catalysis, Ecocatalysis, Hyperaccumulating plants, Phytoextraction

\section{INTRODUCTION}

Epoxides are key building blocks in organic chemistry, notably used for the synthesis of complex natural molecules or as intermediates in the preparation of important commercial products. ${ }^{1-3}$ Olefin epoxidation is one of the main processes by which these compounds are prepared. Classical methods rely for the most part on the use of organic peroxides and peracids, such as $m$-chloroperoxybenzoic acid ( $m$-CPBA). ${ }^{4}$ However, the use of these epoxidation reagents in industrial processes is called into question by recent legislation ${ }^{5,6}$ because their handling is associated with safety issues and produces large amounts of wastes.
The employment of hydrogen peroxide as terminal oxidant for olefin epoxidation is a promising ecofriendly alternative because this reagent is cheap, readily available, safe at usual concentrations (typically $\leq 30 \mathrm{wt} \%$ ), and produces only water as byproduct. ${ }^{8,9}$ However, the reactivity and selectivity of hydrogen peroxide used alone are limited; therefore, additives and catalysts are needed in order to form more reactive intermediate species. Several catalytic systems have been developed, many of which 
involve transition metals. ${ }^{10-12}$ Owing to the depletion of metal resources, new catalysts are required that are inexpensive and that are not based on increasingly scarce metals. ${ }^{13,14}$ Efforts have been made to develop efficient epoxidation catalysts based on $\mathrm{Fe}$ and $\mathrm{Ti}^{15-21} \mathrm{Mn}$ is also a good candidate because it is the third most abundant transition metal in the Earth's crust and is considered to be nontoxic. ${ }^{22,23} \mathrm{Mn}$ is involved in several bio logical oxidations, which have inspired the conception of biomimetic oxidation catalysts such as porphyrin-Mn, salen$\mathrm{Mn}$, phthalocyanin-Mn, and triazamacrocycle-Mn. ${ }^{24,25}$ In spite of the efficiency of these catalysts, their preparation is often difficult and low-yielding. Moreover, because of the homogeneous nature of such catalysts, their loss at the end of the reaction increases the cost and the environmental impact of the process. Heterogeneous epoxidation catalysts based on $\mathrm{Mn}$ have thus been designed by either grafting of the previous homogeneous catalysts on a solid support or immobilization of $\mathrm{Mn}$ derivatives into porous solids. ${ }^{26}$ Incorporation of simple $\mathrm{Mn}$ salts, readily available and cheap, through solid supports such as zeolites, MCM-41, and graphene oxide has been the object of recent interesting work, although the activity of these catalysts proved to be limited to simple and reactive substrates. ${ }^{27-29}$

Ecocatalysis is a recently established area of sustainable catalysis initiated by our group. ${ }^{30,31}$ Taking advantage of the capacity of certain plants to accumulate metallic elements in their cells, ${ }^{32-34}$ the concept consists of the production of biosourced polymetallic catalysts, starting from biomass naturally enriched in trace metals. ${ }^{35-37}$ Crops of metal-hyperaccumulating plants are developed on sites polluted by metallic elements generated by mining activities. Recovery of the resulting biomass, naturally enriched in trace metals, allows a progressive depollution of the contaminated soils. This process, named phytoextraction, thus allows the recycling of metallic elements that are present in soils in concentrations too low to permit recovery by classical mining processes but high enough to be a source of pollution. Thanks to physiological mechanisms of metal-hyperaccumulating plants, the metallic elements are concentrated in their cells with a particular selectivity, specific to each species of plant used. ${ }^{38,39}$ The resulting biomass thus displays an unusual polymetallic composition. Ecocatalysis processes developed by our group consist of producing polymetallic catalysts (named ecocatalysts, "Eco-M", where $\mathrm{M}$ is the metal predominantly accumulated by the plant) starting from this biomass. Thanks to their original structure, these ecocatalysts prove to be highly efficient in various chemical reactions, often leading to selectivity and yield higher than classical catalysts. ${ }^{40-42}$

In this article, we describe the design and the performances of a heterogeneous catalyst produced from plants from New Caledonia that predominantly accumulate $\mathrm{Mn}$ in their leaves. This supported Eco-Mn catalyst demonstrates a high efficiency in the epoxidation of various olefins, including bulky natural molecules, giving yields higher than those obtained with previously described Mn-based heterogeneous catalysts. Moreover, the supported Eco-Mn catalyst also allows a selective access to aldehydes from the starting olefins by simple modification of temperature and reaction time. The methodology thus constitutes a valuable alternative to not only classical methods of epoxidation but also to oxidative cleavage of olefins, which usually involves toxic and polluting reagents. ${ }^{43}$

\section{EXPERIMENTAL SECTION}

Chemicals. Reagents and solvents were purchased from SigmaAldrich and were used without further purification.
Preparation of Eco-Mn Catalyst. Leaves of the Mn-hyperaccumulating plant Grevillea exul subsp. rubiginosa (Proteaceae) were harvested before flowering in the Southern Province of the subtropical Pacific island of New Caledonia from homogeneous plant populations. G. exul subsp. rubiginosa was collected at Col de Mouriange, near Le Mont-Dore. The leaves were air-dried and ground. The obtained solid $(50 \mathrm{~g})$ was calcined at $400{ }^{\circ} \mathrm{C}$ for $5 \mathrm{~h}$, and the resulting powder $(1.5 \mathrm{~g})$ was added to $20 \mathrm{~mL}$ of a dilute solution of $\mathrm{HCl}(1 \mathrm{M})$. The solution was stirred for $2 \mathrm{~h}$ at $60^{\circ} \mathrm{C}$. During the heating, the color of the mixture changed from black to dark green. The reaction mixture was then filtered on a pad of Celite. The resulting dark-green solution, composed of different metal chlorides, was concentrated under vacuum, yielding the Eco-Mn catalyst $(2.25 \mathrm{~g})$. The resulting Eco-Mn catalyst was stored in a desiccator under vacuum. Purification steps are not mandatory in our process.

Incorporation of Eco-Mn Catalyst into Montmorillonite K10. A $500 \mathrm{mg}$ amount of montmorillonite $\mathrm{K} 10$ was added to a solution of Eco-Mn catalyst $\left(250 \mathrm{mg}\right.$ in $10 \mathrm{~mL}$ of water) and stirred at $90{ }^{\circ} \mathrm{C}$ for $8 \mathrm{~h}$. The solid was then recovered by filtration and washed with deionized water $(5 \times 10 \mathrm{~mL})$ until the disappearance of free $\mathrm{Cl}^{-}$ions in the solution was achieved (negative test with $\mathrm{AgNO}_{3}$ ). The resulting supported Eco-Mn catalyst was dried in an oven at $120{ }^{\circ} \mathrm{C}$ for $3 \mathrm{~h}$, then stored in a desiccator under vacuum.

Characterization of the Catalysts. Inductively coupled plasma mass spectrometry (ICP-MS) analyses were carried out using the metal analysis of total dissolved solutes in water. The samples were diluted to $0.005 \mathrm{~g} \cdot \mathrm{L}^{-1}$ with nitric acid $(2.5 \%)$ and stirred for $30 \mathrm{~min}$ until complete dissolution. Analyses of insoluble supported catalysts were carried out after extraction of their metal content by stirring $50 \mathrm{mg}$ of supported catalyst in $5 \mathrm{~mL}$ of a $0.1 \mathrm{M}$ solution of ethylenediaminetetraacetic acid disodium salt dihydrate (EDTA disodium salt) for $24 \mathrm{~h}$ at $25{ }^{\circ} \mathrm{C}$ followed by filtration, according to a procedure adapted from that of Farrah and Pickering. ${ }^{44}$ Analyses were carried out on a HR-ICP-MS Thermo Scientific Element XR. Three blanks were recorded for each step of the dilution procedure. Three analyses were carried out for each sample in order to determine the standard deviation of the measurement.

$\mathrm{X}$-ray diffraction (XRD) analyses were carried out on samples dried at $110^{\circ} \mathrm{C}$ for $2 \mathrm{~h}$ by using a Bruker diffractometer (D8 advance, with a $\mathrm{Cu} \mathrm{K} \alpha$ radiation $\lambda=1.54086 \AA$ ) equipped with a Lynxeyes detector.

$\mathrm{X}$-ray fluorescence spectrometry (XRF) analyses were carried out using a Bruker AXS S4 Explorer wavelength-dispersive spectrometer. The quantitative analysis of major and expected elements was carried out on beaded samples to overcome problems of particle size variation as well as mineralogy effects. The powdered samples were mixed with a $\mathrm{Li}_{2} \mathrm{~B}_{4} \mathrm{O}_{7}$ flux with a flux/sample ratio equal to 8 , heated in a crucible between 400 and $600{ }^{\circ} \mathrm{C}$, and then cast in a platinum dish to produce a homogeneous, glasslike bead.

$\mathrm{X}$-ray photoelectron spectroscopy (XPS) analyses were carried out with an ESCALAB 250 X-ray photoelectron spectrometer from Thermo Electron. The spectra were generated by Al K $\alpha$ X-ray $(1486.6 \mathrm{eV})$. Each sample, under the form of powder, was mounted on a support holder using double-sided conducting adhesive tape. The surface of the sample that is analyzed has a diameter of $400 \mu \mathrm{m}$. All the binding energies were referenced to the $\mathrm{C} 1 \mathrm{~s}$ core-level energy at $284.8 \mathrm{eV}$.

Analysis of Reaction Products. NMR spectra were recorded on a Bruker Avance 300 spectrometer at room temperature. ${ }^{1} \mathrm{H}$ frequency is $300 \mathrm{MHz} ;{ }^{13} \mathrm{C}$ frequency is $75 \mathrm{MHz}$. IR spectra were recorded on a PerkinElmer Spectrum 100 FT-IR spectrometer in ATR mode. GC-MS analyses were carried out on a Shimadzu QP2010SE apparatus equipped with a $30 \mathrm{~m} \times 0.25 \mathrm{~mm} \times 0.25 \mu \mathrm{m}$ ZB-5MSi Guardian column (Phenomenex) with hydrogen as carrier gas.

Representative Procedure for Epoxidation of Alkenes. In a typical procedure, styrene $(28.7 \mu \mathrm{L}, 0.25 \mathrm{mmol})$ was added to a mixture of DMF $(1 \mathrm{~mL})$ and water $(0.6 \mathrm{~mL})$ in a $5 \mathrm{~mL}$ reaction vial equipped with a magnetic stirring bar. The mixture was stirred and cooled to $0{ }^{\circ} \mathrm{C}$ in an ice bath; then, supported Eco-Mn catalyst was added (39 mg, Mn $0.31 \mathrm{~mol} \%$, Fe $1.82 \mathrm{~mol} \%$ ). A freshly prepared mixture of $\mathrm{H}_{2} \mathrm{O}_{2}$ (commercial 30 wt \% solution, $85 \mu \mathrm{L}, 0.8 \mathrm{mmol}$ ) and aqueous $\mathrm{NaHCO}_{3}(0.2 \mathrm{M}$ solution, $250 \mu \mathrm{L}, 0.05 \mathrm{mmol})$ was then 
Table 1. ICP-MS Analysis of Eco-Mn from Grevillea exul subsp. rubiginosa

\begin{tabular}{|c|c|c|c|c|c|c|}
\hline metal composition & $\mathrm{Mg}$ wt $\%( \pm \mathrm{sd})$ & Ca wt $\%( \pm s d)$ & $\mathrm{Al}$ wt $\%( \pm \mathrm{sd})$ & Mn wt $\%( \pm s d)$ & Fe wt $\%( \pm s d)$ & Ni wt \% ( \\
\hline $\begin{array}{l}\text { G. exul subsp. rubiginosa (dry } \\
\text { shoots) }\end{array}$ & & $0.24( \pm 0.0030)$ & $0.017( \pm 0.00014)$ & $0.40( \pm 0.0028)$ & & \\
\hline $\begin{array}{l}\text { Eco-Mn derived from G. exul } \\
\text { subsp rubiginosa }\end{array}$ & $5.26( \pm 0.086)$ & $10.44( \pm 0.17)$ & $0.24( \pm 0.015)$ & $6.72( \pm 0.037)$ & $0.90( \pm 0.0075)$ & $0.040( \pm 0.00039)$ \\
\hline
\end{tabular}

subsp. rubiginosa

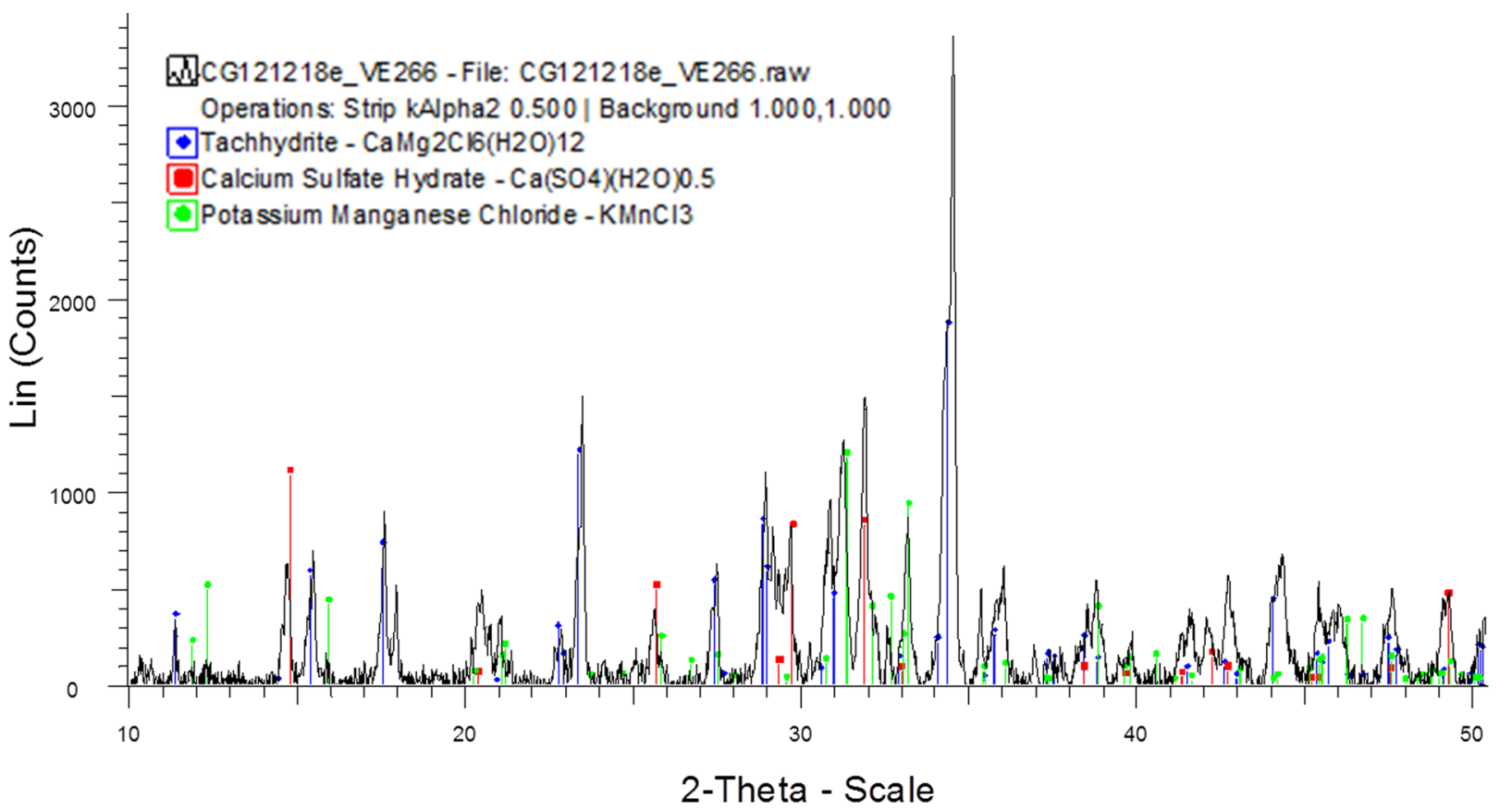

Figure 1. Characterization of Eco-Mn by XRD.

added under stirring to the cooled styrene solution dropwise over $30 \mathrm{~min}$. After $4 \mathrm{~h}$ of reaction at $0{ }^{\circ} \mathrm{C}$, the catalyst was filtered off; the reaction mixture was extracted with diethyl ether and then quantitatively analyzed by GC-MS using biphenyl as internal standard. The recovered catalyst was washed with water $(2 \times 5 \mathrm{~mL})$ then acetone $(2 \times 5 \mathrm{~mL})$ and dried in an oven at $110^{\circ} \mathrm{C}$ for $4 \mathrm{~h}$ before the next run.

Representative Procedure for Oxidative Cleavage of Alkenes. In a typical procedure, styrene $(28.7 \mu \mathrm{L}, 0.25 \mathrm{mmol})$ was added to a mixture of DMF $(1 \mathrm{~mL})$ and water $(0.6 \mathrm{~mL})$ in a $5 \mathrm{~mL}$ reaction vial equipped with a magnetic stirring bar. The mixture was stirred and cooled to $0{ }^{\circ} \mathrm{C}$ in an ice bath; then, supported Eco-Mn catalyst was added ( $39 \mathrm{mg}, \mathrm{Mn} 0.31 \mathrm{~mol} \%$, Fe $1.82 \mathrm{~mol} \%$ ). A freshly prepared mixture of $\mathrm{H}_{2} \mathrm{O}_{2}$ (commercial 30 wt \% solution, $318.8 \mu \mathrm{L}$, $3.0 \mathrm{mmol}$ ) and aqueous $\mathrm{NaHCO}_{3}(0.2 \mathrm{M}$ solution, $250 \mu \mathrm{L}, 0.05 \mathrm{mmol})$ was then added under stirring to the cooled styrene solution dropwise over $30 \mathrm{~min}$. After $4 \mathrm{~h}$ of reaction at $0{ }^{\circ} \mathrm{C}$, the mixture was heated to $80^{\circ} \mathrm{C}$. After $24 \mathrm{~h}$ of heating, the catalyst was filtered off; the reaction mixture was extracted with diethyl ether and then quantitatively analyzed by GC-MS using biphenyl as internal standard.

\section{RESULTS AND DISCUSSION}

Preparation and Characterization of the Catalysts. Eco-Mn catalyst was prepared by extraction of the metal content of leaves of the Mn-hyperaccumulating plant G. exul subsp. rubiginosa. The dried leaves were calcined in air in order to eliminate organic matter. Extraction of the resulting powder was then carried out by treatment with a dilute solution $(1 \mathrm{M})$ of hydrochloric acid then filtration, yielding the metallic elements under the form of soluble chlorides. Polymetallic complexes were then recovered in solid form after concentration of the solution, giving the Eco-Mn catalyst without supplementary purification.
The metal composition of the Eco-Mn catalyst was investigated by ICP-MS after dilution of the solid in an aqueous solution of $2.5 \%$ nitric acid (Table 1 ).

The analysis showed that $\mathrm{Mn}$ was the major transition metal in the ecocatalyst (6.72 wt \%). Small amounts of Fe and Ni were also observed. $\mathrm{Mg}, \mathrm{Ca}$, and $\mathrm{Al}$ were also present because they are essential for plant growth. Because of the natural origin of the Eco-Mn catalyst, some questions may arise concerning the reproducibility of the metal content of the ecocatalyst. The reproducibility of similar ecocatalysts was studied in a previous article, which showed that the levels of transition elements are only slightly variable between samples derived from different plants of the same species. ${ }^{40}$ The Eco-Mn catalyst was prepared from several batches of G. exul subsp. rubiginosa in order to homogenize the content and minimize possible variations in the composition.

XRD analyses were carried out in order to determine the structure of the polymetallic complexes in the Eco-Mn catalyst (Figure 1 and Table 2). Two polymetallic chlorides were

Table 2. Crystalline Species Present in Eco-Mn and Detected by XRD

\begin{tabular}{ll}
\multicolumn{1}{c}{ mineral species } & formula $($ simplified $)$ \\
calcium magnesium chloride hydrate & $\mathrm{CaMg}_{2} \mathrm{Cl}_{6}\left(\mathrm{H}_{2} \mathrm{O}\right)_{12}$ \\
calcium sulfate hydrate & $\mathrm{CaSO}_{4}\left(\mathrm{H}_{2} \mathrm{O}\right)_{0.5}$ \\
potassium manganese chloride & $\mathrm{KMnCl}_{3}$
\end{tabular}

detected: $\mathrm{CaMg}_{2} \mathrm{Cl}_{6}\left(\mathrm{H}_{2} \mathrm{O}\right)_{12}$ and $\mathrm{KMnCl}_{3}$, which was a masked form of $\mathrm{MnCl}_{2}$. Manganese was thus present in Eco-Mn under the oxidation state $\mathrm{Mn}(\mathrm{II})$. 
$\mathrm{XRD}$ did not reveal the presence of molecules containing $\mathrm{Fe}$ or $\mathrm{Al}$, which were detected by elemental analysis. This was probably due to the noncrystalline nature of these species within the Eco-Mn catalyst.

XPS analyses confirmed that Mn was present under the oxidation state $\mathrm{Mn}(\mathrm{II})$ in the Eco-Mn catalyst (Figure 2i)
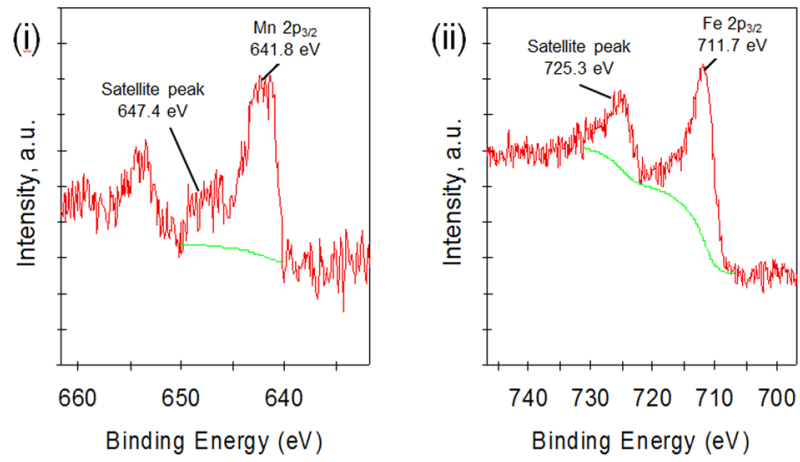

Figure 2. XPS analysis of Eco-Mn showing (i) Mn 2 $\mathrm{p}_{3 / 2}$ peak and (ii) $\mathrm{Fe} 2 \mathrm{p}_{3 / 2}$ peak.

because the spectrum displayed a peak for $\mathrm{Mn} 2 \mathrm{p}_{3 / 2}$ at $641.8 \mathrm{eV}$, with a satellite peak at $647.4 \mathrm{eV}$. This configuration has been described as characteristic of the oxidation state (+II) for $\mathrm{Mn}^{45}$ A similar pattern was observed for Fe (Figure 2ii), with the presence of a peak for $\mathrm{Fe} 2 \mathrm{p}_{3 / 2}$ at $711.7 \mathrm{eV}$, accompanied by a satellite peak at $725.3 \mathrm{eV}$, which is characteristic of $\mathrm{Fe}(\mathrm{III}){ }^{46}$ This oxidation state for Fe was confirmed by a simple colorimetric test with ammonium thiocyanate, showing an intense red coloration upon addition of Eco-Mn, characteristic of $\mathrm{Fe}$ (III) thiocyanate formation. ${ }^{47}$

To ensure the recovery of the Eco-Mn catalyst at the end of the epoxidation reaction, we used montmorillonite K10 as solid support. Previous works have described the preparation and activity of heterogeneous catalysts for epoxidation made by incorporation of $\mathrm{Mn}$ (II) simple salts into other solid supports, such as silica, ${ }^{27}$ siliceous mesoporous material TUD- $1,{ }^{48}$ zeolites $\mathrm{Na}-\mathrm{Y}$, Na-beta, Na-ZSM-5, Na-4 $\AA^{27}$ MCM- $41,{ }^{28}$ or graphene oxide. $^{29}$ Insoluble manganese oxides have also been used as heterogeneous catalysts. ${ }^{49}$ Because montmorillonite $\mathrm{K} 10$ is often used in the preparation of cation-exchanged heterogeneous catalysts, ${ }^{50}$ we decided to investigate the properties of a montmorillonite-K10-supported Eco-Mn catalyst, prepared following an already-described impregnation procedure. ${ }^{27}$ The metal content of the supported Eco-Mn catalyst was determined by XRF (Table 3).

The Mn content in the supported Eco-Mn catalyst was only $0.11 \mathrm{wt} \%$. In the same manner, all the other metals were present in less than $1.00 \mathrm{wt} \%$, except for $\mathrm{Al}$ (6.00 wt \%), which is a natural constituent of montmorillonite $\mathrm{K} 10$ and whose presence is not the result of the incorporation of elements from Eco-Mn. Mn and Fe contents were confirmed by ICP-MS analysis after EDTA extraction of the supported Eco-Mn catalyst. It should be noted that except for $\mathrm{Mn}$ (and $\mathrm{Ni}$ in a lesser extent), all the metal contents are lower in supported Eco-Mn than in pristine $\mathrm{K} 10$, a difference which is particularly marked for Fe. Such leaching of metals originally present in montmorillonite K10 during incorporation of Eco-Mn could be due to the slightly acidic dissolution of Eco-Mn in water (observed $\mathrm{pH}$ was 4), which is a result of the hydrolysis of metal chlorides present in Eco-Mn.

Owing to the very low content of $\mathrm{Mn}$ in the supported Eco-Mn catalyst, it was not possible to observe clearly the corresponding signals in XRD and XPS analyses. Acquired spectra were not significantly different from those of the solid support alone. Only a weak signal related to a $\mathrm{Mn}$ species was detected by XRD (Figure S2). This was attributed to a potassium manganese oxide $\mathrm{K}_{3}\left(\mathrm{MnO}_{4}\right)_{2}$ previously described particularly as a product of thermal decomposition of $\mathrm{KMnO}_{4}{ }^{51-53}$ However, because of the weakness of the signal, this presence remains a hypothesis to be confirmed. We decided to investigate the catalytic performances of the supported Eco-Mn catalyst in order to determine if its low Mn content was sufficient to promote the epoxidation of alkenes.

Optimization of Reaction Conditions. We selected reaction conditions of epoxidation that entail the formation, as epoxidizing species, of peroxymonocarbonate $\left(\mathrm{HCO}_{4}^{-}\right)$produced in situ by mixing hydrogen peroxide and aqueous sodium hydrogen carbonate. ${ }^{54}$ Because these reagents are readily available, cheap, and do not lead to formation of toxic wastes, their use in alkene epoxidation has been studied by several groups. ${ }^{55,56}$ Although these reaction conditions lead to high yields of epoxides, long reaction times (up to $48 \mathrm{~h}$ ) were required under the original conditions. Moreover, these experimental procedures often make use of environmentally unfriendly solvents like DMF. Lane and Burgess discovered that the reaction could be accelerated by catalysis with $\mathrm{Mn}$ (II) simple salts and that DMF could be replaced by $t$-BuOH. ${ }^{57,58}$ The authors formulated several hypotheses about the role of $\mathrm{Mn}$ (II) ions in the catalysis of the reaction, which are still the subject of mechanistic studies. ${ }^{59,60}$ These conditions have been adapted by Qi et al. to the reaction with $\mathrm{Mn}$ (II)-exchanged supports. ${ }^{27} \mathrm{We}$ started our investigation with a test reaction on styrene 1a under these reaction conditions in order to determine the activity of the supported Eco-Mn catalyst. This catalytic activity was compared to those of the sole montmorillonite K10 and of the nonsupported Eco-Mn (Table 4).

We studied the reaction with an equal mass of the three catalysts: The supported Eco-Mn catalyst shows some efficiency with only $0.31 \mathrm{~mol} \% \mathrm{Mn}$ and $1.82 \mathrm{~mol} \%$ Fe because styrene epoxide 2 a was obtained with $41 \%$ yield and $80 \%$ selectivity (Table 4, entry 1). Benzaldehyde was the only other product formed. The comparison with montmorillonite K10 proved that the support alone could not catalyze the reaction (entry 2 ). In the same manner, the nonsupported Eco-Mn was inefficient, even with a high loading of $\mathrm{Mn}(19.57 \mathrm{~mol} \%)$ and Fe (2.58 $\mathrm{mol} \%)$ because only $1 \%$ conversion was observed (entry 3); the Mn and Fe proportions were imposed by the composition of the Eco-Mn catalyst. The absence of reaction with nonsupported Eco-Mn

Table 3. Metal Composition of the Supported Eco-Mn Catalyst as Established by XRF

\begin{tabular}{|c|c|c|c|c|c|c|}
\hline metal composition & Mg wt $\%( \pm s d)$ & Ca wt $\%( \pm s d)$ & $\mathrm{Al}$ wt $\%( \pm \mathrm{sd})$ & Mn wt $\%( \pm s d)$ & Fe wt $\%( \pm s d)$ & $\mathrm{Ni}$ wt $\%( \pm \mathrm{sd})$ \\
\hline pristine montmorillonite $\mathrm{K} 10$ & $1.04( \pm 0.071)$ & $0.27( \pm 0.054)$ & $7.54( \pm 0.060)$ & n.d. ${ }^{a}$ & $2.17( \pm 0.032)$ & n.d. ${ }^{a}$ \\
\hline supported Eco-Mn & $0.70( \pm 0.066)$ & $0.20( \pm 0.0062)$ & $6.00( \pm 0.045)$ & $0.11( \pm 0.0029)$ & $0.65( \pm 0.0045)$ & $0.002( \pm 0.00034)$ \\
\hline
\end{tabular}

$a_{\text {n.d.: not detected. }}$ 
Table 4. Epoxidation of Styrene with Different Catalysts

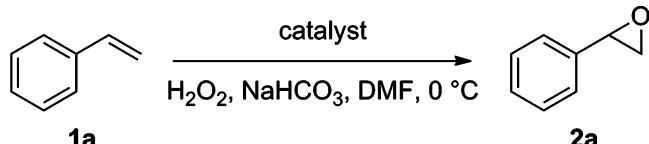

$1 \mathbf{a}$

$2 \mathbf{a}$

\begin{tabular}{|c|c|c|c|c|c|c|}
\hline entry & catalyst & amount of $\mathrm{Mn}(\mathrm{mol} \%)$ & amount of $\mathrm{Fe}(\mathrm{mol} \%)$ & conversion $(\%)^{a, b}$ & yield $(\%)^{b}$ & selectivity (\%) ${ }^{c}$ \\
\hline 1 & supported Eco-Mn & 0.31 & 1.82 & 51 & 41 & 80 \\
\hline 2 & montmorillonite $\mathrm{K} 10$ & & 6.06 & 0 & 0 & n.d. ${ }^{d}$ \\
\hline 3 & Eco-Mn & 19.57 & 2.58 & 1 & 1 & n.d. ${ }^{d}$ \\
\hline
\end{tabular}

${ }^{a}$ Reaction conditions: styrene $(0.25 \mathrm{mmol}), \mathrm{H}_{2} \mathrm{O}_{2}$ (30 wt \%, $\left.0.8 \mathrm{mmol}\right), \mathrm{NaHCO}_{3}(0.2 \mathrm{M}, 0.05 \mathrm{mmol})$, catalysts $(39 \mathrm{mg}), \mathrm{DMF}(2 \mathrm{~mL}), 0{ }^{\circ} \mathrm{C}, 4 \mathrm{~h}$. ${ }^{b}$ Conversion and yield were determined by GC-MS analysis, with biphenyl as internal standard. ${ }^{c}$ Ratio of yield to conversion as a percentage. ${ }^{d}$.d.: not determined.

may be due to the rapid decomposition of the oxidizing mixture of $\mathrm{H}_{2} \mathrm{O}_{2}$ and $\mathrm{NaHCO}_{3}$ because an effervescence was noted upon addition of the catalyst. Chemical analysis of the resulting gas revealed that only $\mathrm{O}_{2}$ was formed, probably by disproportionation of $\mathrm{H}_{2} \mathrm{O}_{2}$ into $\mathrm{O}_{2}$ and $\mathrm{H}_{2} \mathrm{O}$. Such effervescence was not observed with the supported Eco-Mn catalyst.

The influence of the amount of supported Eco-Mn catalyst was then investigated (Figure 3). Conversion of styrene as well

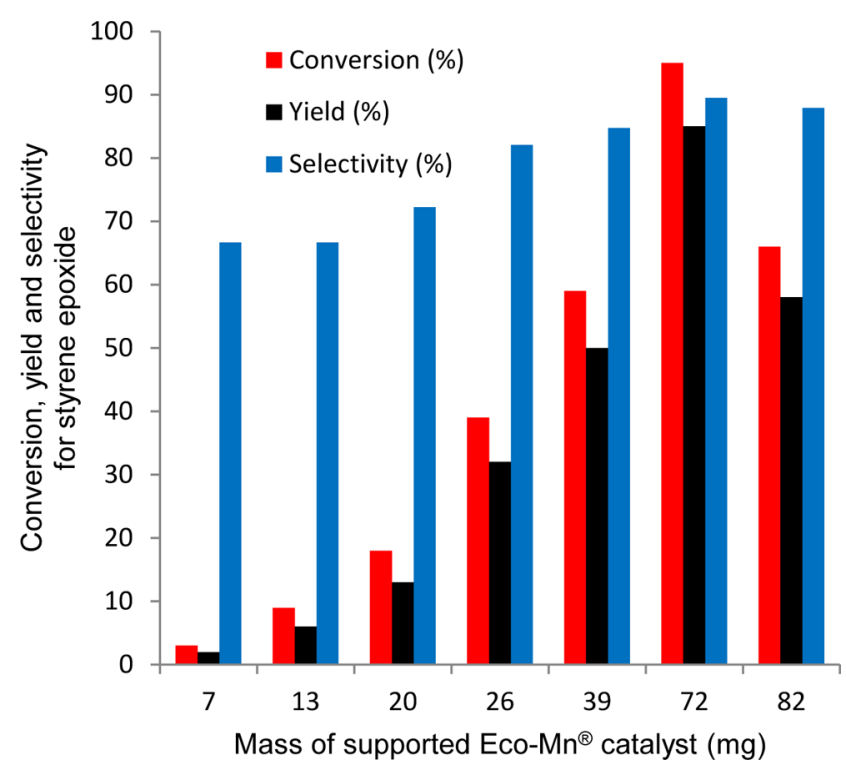

Figure 3. Influence of the amount of supported Eco-Mn catalyst on the conversion, yield of styrene epoxide, and selectivity for this compound. Reaction conditions: styrene $(0.25 \mathrm{mmol}), \mathrm{H}_{2} \mathrm{O}_{2}$ (30 wt \%) $(0.8 \mathrm{mmol}), \mathrm{NaHCO}_{3}(0.2 \mathrm{M})(0.05 \mathrm{mmol}), \mathrm{DMF}(2 \mathrm{~mL}), 0{ }^{\circ} \mathrm{C}, 4 \mathrm{~h}$. Selectivity is expressed as the ratio of yield to conversion.

as yield and selectivity toward styrene epoxide followed the same trend, increasing progressively until an optimum of $72 \mathrm{mg}$ was reached for supported Eco-Mn catalyst, corresponding to $0.58 \mathrm{~mol} \% \mathrm{Mn}$ and $3.35 \mathrm{~mol} \% \mathrm{Fe}$. Beyond this limit, although selectivity remained quite stable, conversion and yield dropped dramatically, owing perhaps to an accelerated decomposition of the oxidizing mixture of $\mathrm{H}_{2} \mathrm{O}_{2}$ and $\mathrm{NaHCO}_{3}$, as observed with high loading of nonsupported Eco-Mn (Table 4, entry 3). A good yield of styrene epoxide (85\%) was thus obtained with low loadings of $\mathrm{Mn}(0.58 \mathrm{~mol} \%)$ and $\mathrm{Fe}(3.35 \mathrm{~mol} \%)$, confirming the efficiency of the supported Eco-Mn catalyst in the reaction.

Solvents other than DMF were tested in order to determine if a greener alternative could be used (Table 5). Previous studies
Table 5. Effect of Various Solvents on the Epoxidation of Styrene Catalyzed by Supported Eco-Mn

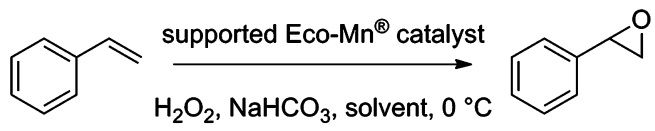

$1 \mathbf{a}$

$2 \mathbf{a}$

\begin{tabular}{clrrl} 
entry & \multicolumn{1}{c}{ solvent } & $\begin{array}{c}\text { conversion } \\
(\%)^{a, b}\end{array}$ & $\begin{array}{c}\text { yield } \\
(\%)^{b}\end{array}$ & $\begin{array}{c}\text { selectivity } \\
(\%)^{c}\end{array}$ \\
1 & DMF & 95 & 85 & 89 \\
2 & acetonitrile & 17 & 17 & 100 \\
3 & 1,2-propylene carbonate & 4 & 4 & 100 \\
4 & dichloromethane & 0 & 0 & n.d. $^{d}$ \\
5 & water & 4 & 4 & 100 \\
6 & isopropanol & 6 & 5 & 83 \\
7 & 4-methyl-2-pentanol & 5 & 4 & 80 \\
8 & glycerol & 6 & 4 & 67 \\
9 & ethanol & 17 & 16 & 94 \\
10 & THF & 8 & 5 & 63 \\
11 & acetone & 18 & 18 & 100 \\
12 & 2-butanone & 5 & 5 & 100
\end{tabular}

${ }^{a}$ Reaction conditions: styrene $(0.25 \mathrm{mmol}), \mathrm{H}_{2} \mathrm{O}_{2}$ (30 wt \%, $\left.0.8 \mathrm{mmol}\right)$, $\mathrm{NaHCO}_{3}(0.2 \mathrm{M}, 0.05 \mathrm{mmol})$, supported Eco-Mn catalyst $(72 \mathrm{mg}, \mathrm{Mn}$ $0.58 \mathrm{~mol} \%$, Fe $3.35 \mathrm{~mol} \%)$, solvent $(2 \mathrm{~mL}), 0{ }^{\circ} \mathrm{C}, 4 \mathrm{~h} .{ }^{b}$ Conversion and yield were determined by GC-MS analysis, with biphenyl as internal standard. ${ }^{c}$ Ratio of yield to conversion as a percentage. ${ }^{d}$ n.d.: not determined.

of epoxidation with $\mathrm{Mn}$ (II)-supported catalysts found that DMF was the best solvent for the reaction, although $t-\mathrm{BuOH}$ was also a possible choice for reactions carried out at room temperature. ${ }^{57,58}$ Because under our conditions the reaction was slightly exothermic, we decided to conduct it at $0{ }^{\circ} \mathrm{C}$, excluding the possibility of using $t$ - $\mathrm{BuOH}$, which is solid at this temperature. 4-Methyl-2-pentanol, still liquid at $0{ }^{\circ} \mathrm{C}$, was tested as an alternative to $t$ - $\mathrm{BuOH}$.

DMF remained effectively the best solvent for the reaction because all the other solvents tested led to a conversion less than 20\%. Even with 1,2-propylene carbonate, which has been described as a green alternative to DMF because of its similar solvation properties, ${ }^{61}$ only $4 \%$ conversion was obtained (Table 5, entry 3). We thus decided to use DMF, but an incidental observation led us to diminish its content in the reaction medium. Indeed, we observed that when we used supported Eco-Mn catalyst that was not perfectly dried the yield of styrene epoxide was slightly better than with anhydrous catalyst. Suspecting an effect due to traces of water, we thus decided to investigate the influence of a controlled addition of water in the reaction medium (Figure 4). 


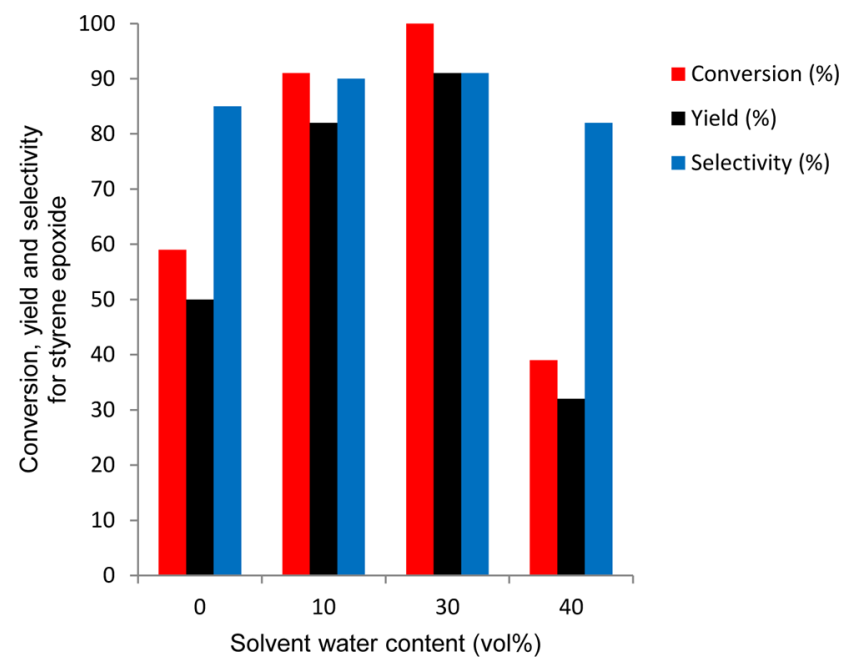

Figure 4. Effect of the addition of water to the reaction medium. Reaction conditions: styrene $(0.25 \mathrm{mmol}), \mathrm{H}_{2} \mathrm{O}_{2}(30 \mathrm{wt} \%)(0.8 \mathrm{mmol})$, $\mathrm{NaHCO}_{3}(0.2 \mathrm{M})(0.05 \mathrm{mmol})$, supported Eco-Mn catalyst (39 mg, Mn $0.31 \mathrm{~mol} \%$, Fe $1.82 \mathrm{~mol} \%), \mathrm{DMF} /$ water $(2 \mathrm{~mL}), 0{ }^{\circ} \mathrm{C}$, $4 \mathrm{~h}$. Selectivity is expressed as the ratio of yield to conversion.

To see the effect of this addition, we started with a lower quantity of supported Eco-Mn catalyst than the previously optimized amount. Although without initial water $39 \mathrm{mg}$ of supported Eco-Mn catalyst for $0.25 \mathrm{mmol}$ of styrene (Mn $0.31 \mathrm{~mol} \%$, Fe $1.82 \mathrm{~mol} \%$ ) gave 59\% conversion, addition of $10 \mathrm{vol} \%$ water caused an increase to $91 \%$ conversion. An optimum was reached at $30 \mathrm{vol} \%$ water, with quantitative conversion of styrene and $91 \%$ yield of styrene epoxide. Selectivity increased equally with the addition of water. Beyond $30 \mathrm{vol} \%$ water, conversion dropped because of the insolubility of styrene in the solvent mixture. The positive effect of water on reaction efficiency was quite surprising, but Richardson et al. ${ }^{62}$ mentioned a similar observation when a $\mathrm{H}_{2} \mathrm{O}_{2} / \mathrm{NaHCO}_{3}$ mixture was used for the oxidation of sulfides. According to those authors, addition of water led to an increase in conversion because of the better solubility of the oxidizing peroxymonocarbonate $\mathrm{HCO}_{4}^{-}$in moist solvents. A similar effect allowed us to obtain a quantitative conversion of styrene with a reduced amount of supported Eco-Mn catalyst ( $\mathrm{Mn} 0.31 \mathrm{~mol} \%$; Fe $1.82 \mathrm{~mol} \%$ ), while lowering the content of environmentally unfriendly DMF in the total volume of solvent. Addition of water in the other tested solvents (Table 5) did not give significant improvements mainly because of the insolubility of styrene in these solvent mixtures.

Even if water addition allowed a reduction in catalyst amount from 72 to $39 \mathrm{mg}$ for $0.25 \mathrm{mmol}$ of styrene, the mass ratio remains quite high. This is due to the highly diluted character of the active species in the supported Eco-Mn catalyst, which contains only $0.11 \mathrm{wt} \% \mathrm{Mn}$. The mineral matrix, composed of the solid support and other elements from Eco-Mn catalyst, represents an important volume but allows an efficient recycling of the catalyst (see below). From the perspective of an application of the procedure on a large scale, the reaction medium remains fluid even with this mass ratio of catalyst versus substrate. Agitation is not a problem, and filtration is easy.

The importance of slow dropping of $\mathrm{H}_{2} \mathrm{O}_{2}$ in epoxidation reactions has been underlined in previous papers, demonstrating its impact on the selectivity of the reaction and on $\mathrm{H}_{2} \mathrm{O}_{2}$ decomposition. ${ }^{19-21}$ The amount of residual $\mathrm{H}_{2} \mathrm{O}_{2}$ was thus measured (titration by manganimetry, ${ }^{63}$ average of three runs) at the end of the reaction in the proposed conditions. A residual amount of $0.28 \mathrm{mmol}$ of $\mathrm{H}_{2} \mathrm{O}_{2}$ was determined, indicating a decomposition of $34 \mathrm{~mol} \%$ the total load of $\mathrm{H}_{2} \mathrm{O}_{2}$, by disproportionation into $\mathrm{O}_{2}$ and $\mathrm{H}_{2} \mathrm{O}$.

Recycling and Leaching Studies. Using these new reaction conditions, we studied the recycling of the supported Eco-Mn catalyst and its possible leaching. The recycling was carried out four times, after filtration, washing, and then drying of the supported Eco-Mn catalyst (Table 6).

Conversion and yield remained unchanged after the fourth recycling, indicating high stability of the supported Eco-Mn catalyst, even in the oxidizing conditions of the reaction. Starting with a content of 0.11 wt \% Mn, a small decrease was first observed; then, the value stayed stable around 0.080 wt \% over the following four runs. The Fe content, initially 0.65 wt \%, remained virtually unchanged even after the fourth recycling, confirming the quasi-absence of leaching of the catalyst, even in the aqueous medium used. These observations were confirmed by a filtration test, carried out at the temperature of the reaction, as described by Sheldon et al. ${ }^{64}$ After 30 min of reaction, the catalyst was filtered, and the conversion determined to be $67 \%$ (selectivity 91\%). The filtrate was allowed to react further, until $4 \mathrm{~h}$ of reaction. The resulting conversion was then $80 \%$ (selectivity $88 \%$ ), whereas in a parallel blank test without filtration, conversion reached $98 \%$ (selectivity 90\%). The significant difference in conversion observed between filtered and nonfiltered reactions demonstrates that although leaching

Table 6. Recycling and Leaching Studies of the Supported Eco-Mn Catalyst

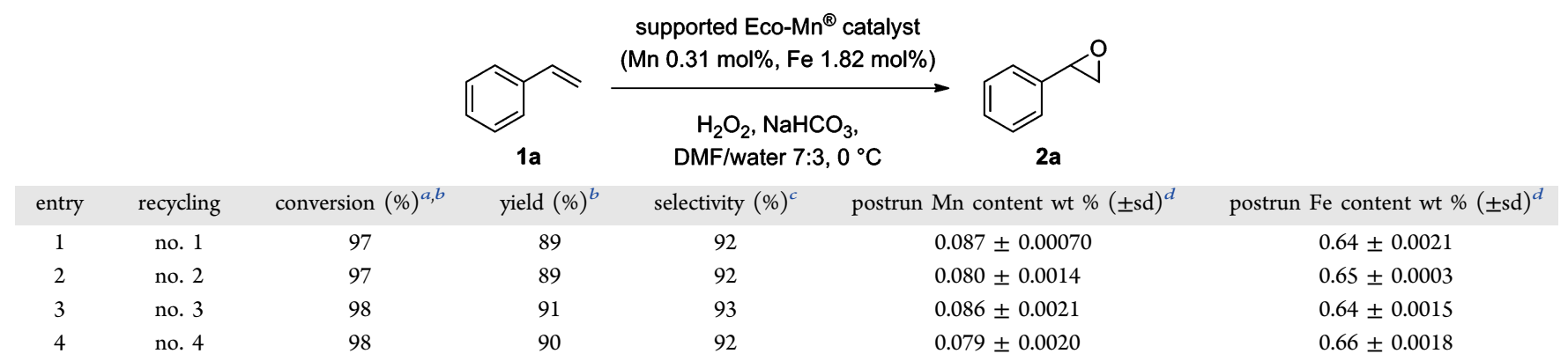

${ }^{a}$ Reaction conditions: styrene $(0.25 \mathrm{mmol}), \mathrm{H}_{2} \mathrm{O}_{2}(30 \mathrm{wt} \%, 0.8 \mathrm{mmol}), \mathrm{NaHCO}_{3}(0.2 \mathrm{M}, 0.05 \mathrm{mmol})$, recycled supported Eco-Mn catalyst (39 mg, $\mathrm{Mn} 0.31 \mathrm{~mol} \%$, Fe $1.82 \mathrm{~mol} \%), \mathrm{DMF} /$ water $7: 3(2 \mathrm{~mL}), 0{ }^{\circ} \mathrm{C}, 4 \mathrm{~h} .{ }^{b}$ Conversion and yield were determined by GC-MS analysis, with biphenyl as internal standard. ${ }^{c}$ Ratio of yield to conversion as a percentage. ${ }^{d}$ Determined by ICP-MS after EDTA extraction of a sample of supported Eco-Mn catalyst after reaction. 
Table 7. Comparison of Catalysts Made with Biosourced and Commercial Mn(II) and Fe(III) Salts

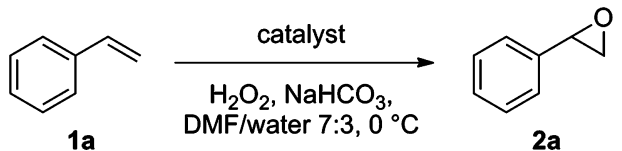

\begin{tabular}{|c|c|c|c|c|c|c|}
\hline entry & catalyst & $\begin{array}{l}\text { amount of Mn used for } \\
\text { the preparation (mmol) }\end{array}$ & $\begin{array}{l}\text { amount of Fe used for } \\
\text { the preparation }(\mathrm{mmol})\end{array}$ & $\underset{(\%)^{a, b}}{\operatorname{conversion}}( \pm \mathrm{sd})$ & $\underset{(\%)}{\operatorname{yield}}\left(\frac{ \pm}{b} \mathrm{sd}\right)$ & $\begin{array}{l}\text { selectivity } \\
( \pm \mathrm{sd})(\%)^{c}\end{array}$ \\
\hline 1 & K10-supported Eco-Mn & 0.31 & 0.040 & $100( \pm 0)$ & $91( \pm 1)$ & $91( \pm 1)$ \\
\hline 2 & $\mathrm{~K} 10$-supported $\mathrm{MnCl}_{2} \cdot 4 \mathrm{H}_{2} \mathrm{O}$ & 0.31 & & $97( \pm 4)$ & $83( \pm 3)$ & $86( \pm 2)$ \\
\hline 3 & K10-supported $\mathrm{FeCl}_{3} \cdot 6 \mathrm{H}_{2} \mathrm{O}$ & & 0.040 & $5( \pm 1)$ & $2( \pm 1)$ & $40( \pm 8)$ \\
\hline 4 & K10-supported $\mathrm{MnCl}_{2} \cdot 4 \mathrm{H}_{2} \mathrm{O} / \mathrm{FeCl}_{3} \cdot 6 \mathrm{H}_{2} \mathrm{O}$ & 0.31 & 0.040 & $98( \pm 1)$ & $86( \pm 1)$ & $88( \pm 2)$ \\
\hline
\end{tabular}

${ }^{a}$ Reaction conditions: styrene $(0.25 \mathrm{mmol}), \mathrm{H}_{2} \mathrm{O}_{2}$ (30 wt \%, $\left.0.8 \mathrm{mmol}\right), \mathrm{NaHCO}_{3}(0.2 \mathrm{M}, 0.05 \mathrm{mmol})$, catalysts $(39 \mathrm{mg}), \mathrm{DMF} /$ water 7:3 (2 mL), $0{ }^{\circ} \mathrm{C}, 4 \mathrm{~h} .{ }^{b}$ Conversion and yield were determined by GC-MS analysis, with biphenyl as internal standard. Average of 4 runs. ${ }^{c}$ Ratio of yield to conversion as a percentage.

traces of Mn cannot be totally excluded the active species are of heterogeneous character in the supported Eco-Mn catalyst.

Comparison with Supported Commercial Simple Salts of $\mathrm{Mn}$ (II) and $\mathrm{Fe}$ (III). To determine the origin of the activity of the supported Eco-Mn catalyst, we prepared similar catalysts with montmorillonite-K10-supported commercial salts of $\mathrm{Mn}(\mathrm{II})$ and $\mathrm{Fe}(\mathrm{III})$. The procedure used for the preparation of the supported Eco-Mn catalyst was followed with $\mathrm{MnCl}_{2} \cdot 4 \mathrm{H}_{2} \mathrm{O}$, $\mathrm{FeCl}_{3} \cdot 6 \mathrm{H}_{2} \mathrm{O}$, and a mixture of these salts. The proportions of salts used were the same as in the starting nonsupported Eco$\mathrm{Mn}$. Their catalytic activity was then tested under the same conditions as for the supported Eco-Mn catalyst (Table 7).

Reaction with $\mathrm{K} 10$-supported $\mathrm{MnCl}_{2} \cdot 4 \mathrm{H}_{2} \mathrm{O}$ gave $97 \%$ conversion of styrene and $83 \%$ yield of styrene epoxide, values similar to those obtained with the supported Eco-Mn catalyst (Table 7, entries 1 and 2). Supported $\mathrm{FeCl}_{3} \cdot 6 \mathrm{H}_{2} \mathrm{O}$ led to an almost absence of reaction, with only $5 \%$ conversion of styrene (entry 3). These results proved that the activity of the supported Eco-Mn catalyst was effectively due to $\mathrm{Mn}$ (II) species, whereas $\mathrm{Fe}$ (III) had only a very limited role in the catalysis. A third catalyst, made with incorporation of a mixture of $\mathrm{MnCl}_{2} \cdot 4 \mathrm{H}_{2} \mathrm{O}$ and $\mathrm{FeCl}_{3} \cdot 6 \mathrm{H}_{2} \mathrm{O}$ in montmorillonite $\mathrm{K} 10$, was tested to investigate a possible synergistic effect of the metallic elements (entry 4). Conversion (98\%), yield (86\%), and selectivity $(88 \%)$ were slightly better with this catalyst than with the supported $\mathrm{MnCl}_{2} \cdot 4 \mathrm{H}_{2} \mathrm{O}$, confirming the interest of the polymetallic catalysis. However, these values were lower than those obtained with the supported Eco-Mn catalyst, proving that the efficiency of this biosourced catalyst was due to particular complexes of the metallic elements accumulated in the starting biomass. The use of supported Eco-Mn catalyst is thus beneficial in terms of efficiency in two ways: First, it displays a superior activity in styrene epoxidation than $\mathrm{MnCl}_{2} \cdot 4 \mathrm{H}_{2} \mathrm{O}$. Second, Eco$\mathrm{Mn}$ is a more desirable form of the metal because it is reclaimed from polluted soils. Although the process requires energy and time to extract Eco-Mn from the Mn-hyperaccumulating plant, this approach is one of the very few ways of valorization of biomass derived from phytoextraction. ${ }^{65-67}$ In traditional mining operations, ecological rehabilitation of degraded soils is seen only as a negative obligation and constraint. The use of Eco-Mn derived from Mn-hyperaccumulating plants could change this perspective. Ecocatalysis increases the value of this biomass, thus changing the legal obligation of restoration into new scientific and financial opportunities.

Substrate Scope of the Supported Eco-Mn-Catalyzed Epoxidation of Alkenes. On the basis of the above studies, the epoxidation of further alkenes was carried out to determine the substrate scope of the method (Table 8). In some cases, the alkenes were not soluble in the DMF/water 7:3 mixture, resulting in poor conversion. When necessary, the percentage of water was therefore reduced. For all the tested substrates, the beneficial effect of water was confirmed, providing that the alkene remained soluble in the solvent mixture. For cases where the tested alkene was not soluble, the addition of a surfactant agent (sodium dodecyl sulfate) was examined but did not significantly improve the conversion.

A first test with norbornene $\mathbf{1 b}$ confirmed the efficiency of the method, giving $99 \%$ yield of norbornene epoxide $\mathbf{2 b}$ (Table 8, entry 1). Reactions on (R)-(+)-limonene $\mathbf{1 c}$ and citral If (entries 2 and 5) indicated that electron-rich double bonds are selectively epoxidized. A moderate activity was noted with $(R)-(+)$-pulegone $1 \mathrm{~g}$, whose $\mathrm{C}-\mathrm{C}$ double bond is highly deactivated by conjugation with carbonyl (entry 6 ). The method proved to be efficient even on bulky natural products, such as $\alpha$-pinene $1 \mathrm{~d}$, giving $75 \%$ yield of $\alpha$-pinene epoxide $\mathbf{2 d}$ with complete selectivity (entry 3 ). Previously described Mn(II)zeolite catalysts were much less effective, showing the interest of the supported Eco-Mn catalyst. ${ }^{27}$ According to literature, linalool epoxide rearranges as soon as formed to give a cyclized product (2e) with $63 \%$ yield. ${ }^{68}$ Fair to good yields of epoxides were obtained on complex and bulky structures, such as nopol 1j (74\%, entry 9) and $\beta$-caryophyllene $1 \mathbf{k}$ (42\%, entry 10$)$, with excellent selectivity. However, the method was inefficient on terminal aliphatic alkenes, such as $n$-octene 11, as already observed with other $\mathrm{Mn}$ (II)-based catalysts (entry 11). ${ }^{27,58}$ By contrast, indene $\mathbf{1 m}$, cyclooctene $1 \mathrm{n}$, and cyclohexene 10 gave epoxides with much higher yields than previously described with $\mathrm{Mn}(\mathrm{II})$-zeolite catalysts (entries 12-14). Cyclooctene epoxide 2n was thus formed in yield nearly double the values reported with other Mn-derived catalysts. ${ }^{27}$

Extension of the Method to Oxidative Cleavage of Alkenes. During optimization of styrene epoxidation, we always observed the formation of a small amount of benzaldehyde. We tried to determine if it was possible to obtain this aldehyde selectively, starting from the alkene. We started our study with the effect of temperature, by heating the reaction medium to $80{ }^{\circ} \mathrm{C}$ instead of cooling to $0{ }^{\circ} \mathrm{C}$, but no reaction was observed because the alkene remained unchanged. In contrast, when we used the previous epoxidation conditions $\left(4 \mathrm{~h}\right.$ at $\left.0{ }^{\circ} \mathrm{C}\right)$ and then heated the medium to $80{ }^{\circ} \mathrm{C}$, after formation of the styrene epoxide, a significant increase in benzaldehyde yield was observed. To reach a nearly quantitative yield of benzaldehyde, however, it was necessary to increase reaction time and amount of hydrogen peroxide (Table 9, entries 1-2). 
Table 8. Substrate Scope of the Supported Eco-Mn-Catalyzed Epoxidation

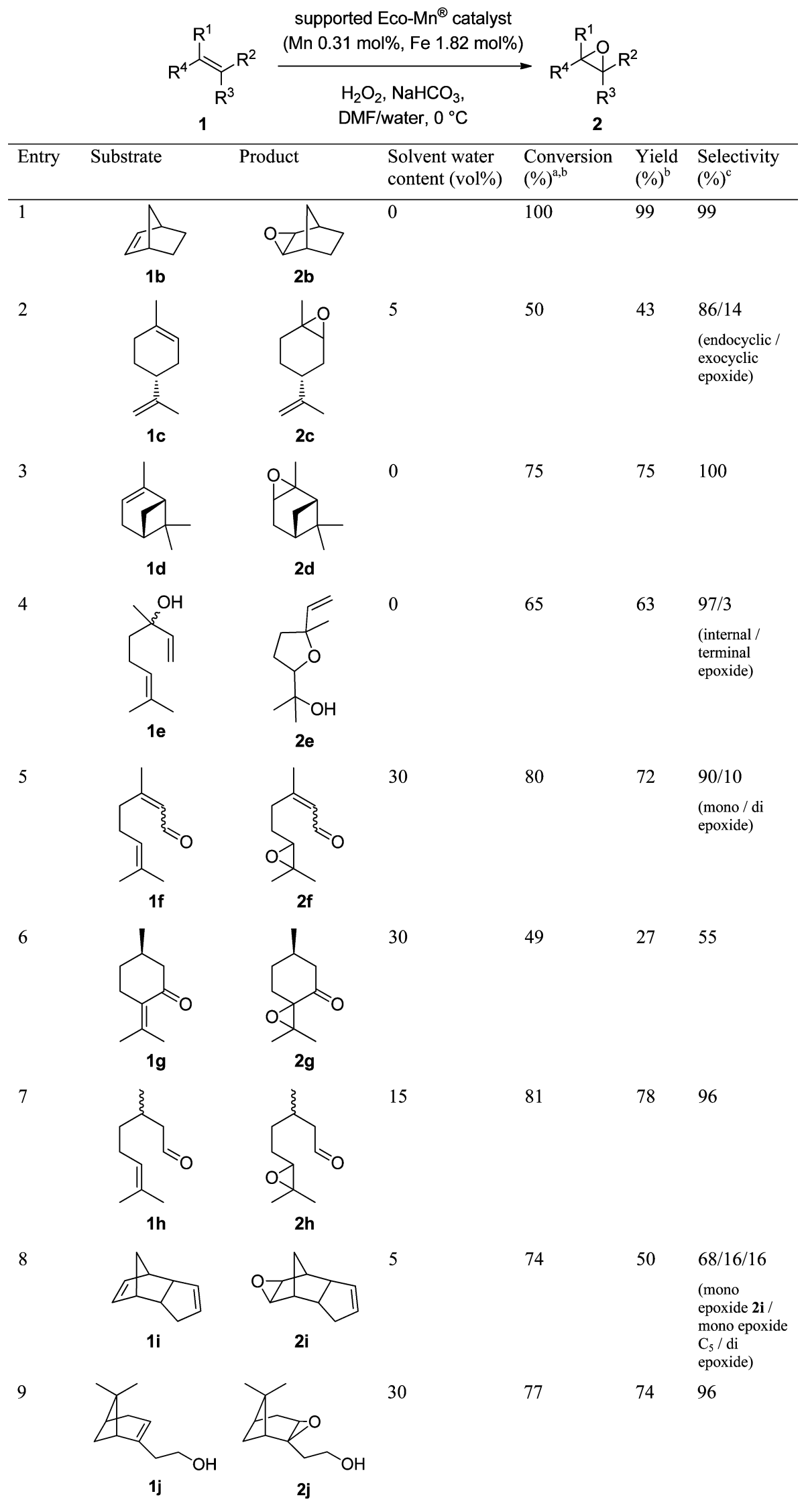


Table 8. continued

Entry

${ }^{a}$ Reaction conditions: alkene $(0.25 \mathrm{mmol}), \mathrm{H}_{2} \mathrm{O}_{2}(30 \mathrm{wt} \%, 0.8 \mathrm{mmol}), \mathrm{NaHCO}_{3}(0.2 \mathrm{M}, 0.05 \mathrm{mmol})$, supported Eco-Mn catalyst (39 mg, Mn $0.31 \mathrm{~mol} \%$, Fe $1.82 \mathrm{~mol} \%)$, DMF/water $(2 \mathrm{~mL}), 0{ }^{\circ} \mathrm{C}, 4 \mathrm{~h} .{ }^{b}$ Conversion and yield were determined by GC-MS analysis, with biphenyl as internal standard. Synthesized products were identified by comparison of their spectroscopic data with those previously published. ${ }^{c}$ Ratio of yield to conversion as a percentage. ${ }^{d}$ n.d.: not determined.

The presence of 1-phenyl-1,2-ethanediol (28\% yield after $10 \mathrm{~h}$, entry 1) and then its disappearance while benzaldehyde was formed in nearly quantitative yield (after $24 \mathrm{~h}$, entry 2) was an indication of the possible mechanism. The epoxide formed initially was probably opened by hydrolysis into a 1,2-diol under catalysis by supported Eco-Mn catalyst. (Without the catalyst, styrene remained unchanged.) The 1,2-diol then underwent an oxidative cleavage into aldehyde. Tests starting directly from styrene epoxide or 1-phenyl-1,2-ethanediol led to nearly quantitative yields of benzaldehyde after $24 \mathrm{~h}$, which confirms the mechanism hypothesis. This oxidative cleavage seemed to be specific to the supported Eco-Mn catalyst because only $24 \%$ yield of benzaldehyde was observed with supported commercial $\mathrm{MnCl}_{2} \cdot 4 \mathrm{H}_{2} \mathrm{O} / \mathrm{FeCl}_{3} \cdot 6 \mathrm{H}_{2} \mathrm{O}$ prepared under the same conditions as the supported Eco-Mn catalyst (entry 3). This reaction with supported commercial $\mathrm{MnCl}_{2} \cdot 4 \mathrm{H}_{2} \mathrm{O} / \mathrm{FeCl}_{3}$. $6 \mathrm{H}_{2} \mathrm{O}$ produced $71 \%$ yield of 1,2 -diol, showing that the limiting step was not the formation of 1,2-diol but rather its cleavage. Only the original composition of the supported Eco-Mn catalyst allowed the conversion of styrene into benzaldehyde with $93 \%$ yield (entry 2 ).

Further alkenes were tested to determine the scope and limitations of the reaction. Presence of electron-withdrawing groups on the aromatic ring seemed to be unfavorable because only $11 \%$ yield of aldehyde $3 \mathrm{c}$ was obtained starting from 3-chlorostyrene 1q (entry 5). Because the corresponding epoxide was however formed in $68 \%$ yield, this indicated that the limiting step was the opening of the epoxide. trans-Anethole 1p, bearing both a methyl-enriched $\mathrm{C}-\mathrm{C}$ double bond and a methoxyenriched aromatic ring, gave a better yield of $p$-anisaldehyde $\mathbf{3 b}$ ( $51 \%$ yield, entry 4$)$.

Reaction with cinnamyl acetate $\mathbf{1 r}$ (entry 6) furnished interesting information on the mechanism. After heating, 53\% yield of benzaldehyde was obtained, in line with our expectations, but $19 \%$ yield of cinnamaldehyde was also observed. Formation of cinnamaldehyde could not be explained by oxidative cleavage of the 1,2-diol after epoxide hydrolysis. Cinnamaldehyde was probably formed by hydrolysis of the acetate into cinnamyl alcohol, which was then oxidized into cinnamaldehyde. Such oxidation of an allylic alcohol is characteristic of the oxidizing activity of $\mathrm{Mn}(\mathrm{IV})$, producing aldehydes without further oxidation into carboxylic acid, as is usually observed with most oxidizing reagents. ${ }^{69,70}$ It is thus possible that $\mathrm{Mn}(\mathrm{II})$ present in the supported Eco-Mn catalyst was oxidized into $\mathrm{Mn}(\mathrm{IV})$ by hydrogen peroxide, the formed $\mathrm{Mn}(\mathrm{IV})$ thus being responsible for the cinnamyl alcohol oxidation. $\mathrm{Mn}(\mathrm{IV})$ could be the active species responsible for the oxidative cleavage of 1,2-diols into aldehydes under our conditions because this reaction was already reported. ${ }^{71}$ Oxidation of $\mathrm{Mn}(\mathrm{II})$ into $\mathrm{Mn}(\mathrm{IV})$ by $\mathrm{H}_{2} \mathrm{O}_{2} / \mathrm{NaHCO}_{3}$ was proposed by Lane et al. ${ }^{58}$

The residual amount of $\mathrm{H}_{2} \mathrm{O}_{2}$ at the end of the reaction was $0.25 \mathrm{mmol}$, which corresponds to $75 \mathrm{~mol} \%$ decomposition of the initial amount of $\mathrm{H}_{2} \mathrm{O}_{2}$ (in the hypothesis of oxidative cleavage by $\mathrm{Mn}(\mathrm{IV})$, consuming one molar equivalent of $\mathrm{H}_{2} \mathrm{O}_{2}$ for epoxidation and one more for the cleavage). This high value is in accordance with previous observations of the accelerated decomposition of $\mathrm{H}_{2} \mathrm{O}_{2}$ during heating in the presence of catalysts. $^{19-21}$

These results thus confirmed the interest of the supported Eco-Mn catalyst, giving selectively epoxides or aldehydes, by simple adjustments of the amount of $\mathrm{H}_{2} \mathrm{O}_{2}$ and reaction conditions. Tests on aliphatic alkenes showed that the present reaction conditions are limited to styrene-derived compounds. Further optimization of the oxidative cleavage on a larger set of substrates is in progress. 
Table 9. Oxidative Cleavage of Alkenes with the Modified Procedure

Catalyst
3

${ }^{a}$ Reaction conditions: alkene $(0.25 \mathrm{mmol}), \mathrm{H}_{2} \mathrm{O}_{2}(30 \mathrm{wt} \%, 3.0 \mathrm{mmol}), \mathrm{NaHCO}_{3}(0.2 \mathrm{M}, 0.05 \mathrm{mmol})$, catalysts (39 mg, $\mathrm{Mn} 0.31 \mathrm{~mol} \%, \mathrm{Fe}$ $1.82 \mathrm{~mol} \%), \mathrm{DMF} /$ water $7: 3(2 \mathrm{~mL}), 0{ }^{\circ} \mathrm{C}$ for $4 \mathrm{~h}$, then $80{ }^{\circ} \mathrm{C}$ for $10-24 \mathrm{~h} .{ }^{b}$ Conversion and yield were determined by GC-MS analysis, with biphenyl as internal standard. Synthesized products were identified by comparison of their spectroscopic data with those previously published. ${ }^{c}$ Ratio of yield to conversion as a percentage. ${ }^{d} 1$-Phenyl-1,2-ethanediol is obtained as side product with $28 \%$ yield. ${ }^{e} 1$-Phenyl-1,2-ethanediol is obtained as side product with $71 \%$ yield. ${ }_{3}$-Chlorostyrene epoxide is formed with $68 \%$ yield. ${ }^{g}$ Cinnamaldehyde is obtained as side product with $19 \%$ yield.

\section{CONCLUSIONS}

Starting from the manganese-hyperaccumulating plant G. exul subsp. rubiginosa, we prepared a heterogeneous Eco-Mn catalyst by incorporation of biosourced polymetallic complexes into montmorillonite K10 as solid support. Characterization by ICPMS, XRD, XRF, and XPS revealed that $\mathrm{Mn}$ (II) and Fe(III) were present in the catalyst. Unusual polymetallic complexes, such as $\mathrm{KMnCl}_{3}$, were observed. After reaction conditions were optimized, the supported Eco-Mn catalyst demonstrated a high activity in alkene epoxidation, with only $0.31 \mathrm{~mol} \% \mathrm{Mn}$, which proved to be the main active species. An interesting effect of the presence of water, which increased the efficiency of the method, was observed. Supported commercial salts of $\mathrm{Mn}$ (II) and $\mathrm{Fe}(\mathrm{III})$, although demonstrating good activity, were not as active and selective as the supported Eco-Mn catalyst, confirming the interest of polymetallic catalysis by the original species present in the biosourced catalyst. The supported Eco-Mn catalyst was recycled four times with no loss of activity. The scope of the methodology was investigated on a wide range of alkenes, including bulky natural products that were epoxidized in fair to excellent yields (up to 99\%). In several cases, the supported Eco-Mn catalyst gave much higher yields of epoxides than previously described Mn-derived heterogeneous catalysts. Finally, by a simple adjustment of reaction conditions, the method provided selective access to aldehydes by oxidative cleavage of the starting alkene. This result proved to be particularly interesting because it may provide an alternative to the use of classical oxidative cleavage reagents, which are often toxic and environmentally hazardous. Further investigation is in progress to identify the active polymetallic species of the Eco-Mn catalyst because there is no doubt that they will continue to display very interesting properties for cutting-edge catalysis.

\section{ASSOCIATED CONTENT}

X-ray diffraction spectrum of Eco-Mn, detailed XPS spectra of Eco-Mn, ICP-MS analysis of Eco-Mn, and MS spectra of synthesized compounds. (PDF) 


\section{AUTHOR INFORMATION}

\section{Corresponding Author}

*E-mail: claude.grison@cnrs.fr.

\section{Notes}

The authors declare no competing financial interest.

\section{ACKNOWLEDGMENTS}

We thank the Agence Nationale de la Recherche (ANR, programme 11ECOT 01101 ), the Agence de l'Environnement et de la Maitrise de l'Energie (ADEME), the Centre National de la Recherche Scientifique (CNRS), and the Fond Européen de Développement Régional (FEDER) for financial support. Prof. Doyle McKey is greatly acknowledged for helpful discussions and proofreading the manuscript.

\section{REFERENCES}

(1) Yudin, A. K. Aziridines and Epoxides in Organic Synthesis; WileyVCH: Weinheim, Germany, 2006.

(2) Das, B.; Damodar, K. In Heterocycles in Natural Product Synthesis; Majumdar, K. C., Chattopadhyay, S. K., Eds.; Wiley-VCH Verlag: Weinheim, Germany, 2011; pp 63-96.

(3) Xia, Q. H.; Ge, H. Q.; Ye, C. P.; Liu, Z. M.; Su, K. X. Advances in homogeneous and heterogeneous catalytic asymmetric epoxidation. Chem. Rev. 2005, 105, 1603-1662.

(4) Sienel, G.; Rieth, R.; Rowbottom, K. T. In Ullmann's Encyclopedia of Industrial Chemistry; Wiley: New York, 2000.

(5) Wilson, M.; Schwarzman, M. Toward a New U.S. Chemicals Policy: Rebuilding the Foundation to Advance New Science, Green Chemistry, and Environmental Health. Environ. Health Perspect. 2009, $117,1202-1209$.

(6) Lahl, U.; Hawxwell, K. A. REACH-The New European Chemicals Law. Environ. Sci. Technol. 2006, 40, 7115-7121.

(7) Adams, J. P.; Alder, C. M.; Andrews, I.; Bullion, A. M.; CampbellCrawford, M.; Darcy, M. G.; Hayler, J. D.; Henderson, R. K.; Oare, C. A.; Pendrak, I.; Redman, A. M.; Shuster, L. E.; Sneddon, H. F.; Walker, M. D. Development of GSK's reagent guides - embedding sustainability into reagent selection. Green Chem. 2013, 15, 15421549.

(8) Grigoropoulou, G.; Clark, J. H.; Elings, J. A. Recent developments on the epoxidation of alkenes using hydrogen peroxide as an oxidant. Green Chem. 2003, 5, 1-7.

(9) Rao, A. S.; Mohan, H. R.; Iskra, J. Hydrogen Peroxide. In Encyclopedia of Reagents for Organic Synthesis; John Wiley \& Sons, Ltd: New York, 2001.

(10) Joergensen, K. A. Transition-Metal-Catalyzed Epoxidations. Chem. Rev. 1989, 89, 431-458.

(11) Lane, B. S.; Burgess, K. Metal-catalyzed epoxidations of alkenes with hydrogen peroxide. Chem. Rev. 2003, 103, 2457-2473.

(12) Arends, I. W. C. E. Metal-Catalyzed Asymmetric Epoxidations of Terminal Olefins Using Hydrogen Peroxide as the Oxidant. Angew. Chem., Int. Ed. 2006, 45, 6250-6252.

(13) Izatt, R. M.; Izatt, S. R.; Bruening, R. L.; Izatt, N. E.; Moyer, B. A. Challenges to achievement of metal sustainability in our high-tech society. Chem. Soc. Rev. 2014, 43, 2451-2475.

(14) Hunt, A. J.; Farmer, T. J.; Clark, J. H. In Element Recovery and Sustainability; Hunt, A. J., Ed.; The Royal Society of Chemistry: Cambridge, U.K., 2013; pp 1-28.

(15) Schroder, K.; Enthaler, S.; Join, B.; Junge, K.; Beller, M. IronCatalyzed Epoxidation of Aromatic Olefins and 1,3-Dienes. Adv. Synth. Catal. 2010, 352, 1771-1778.

(16) Hasan, K.; Brown, N.; Kozak, C. M. Iron-catalyzed epoxidation of olefins using hydrogen peroxide. Green Chem. 2011, 13, 12301237.

(17) Sawada, Y.; Matsumoto, K.; Katsuki, T. Titanium-Catalyzed Asymmetric Epoxidation of Non-Activated Olefins with Hydrogen Peroxide. Angew. Chem. 2007, 119, 4643-4645.
(18) Nur, H.; Ikeda, S.; Ohtani, B. Phase-Boundary Catalysis of Alkene Epoxidation with Aqueous Hydrogen Peroxide Using Amphiphilic Zeolite Particles Loaded with Titanium Oxide. J. Catal. 2001, 204, 402-408.

(19) Fraile, J. M.; García, J. I.; Mayoral, J. A.; Vispe, E. Optimization of cyclohexene epoxidation with dilute hydrogen peroxide and silicasupported titanium catalysts. Appl. Catal., A 2003, 245, 363-376.

(20) Timofeeva, M. N.; Kholdeeva, O. A.; Jhung, S. H.; Chang, J. S. Titanium and cerium-containing mesoporous silicate materials as catalysts for oxidative cleavage of cyclohexene with $\mathrm{H} 2 \mathrm{O} 2$ : A comparative study of catalytic activity and stability. Appl. Catal., A 2008, 345, 195-200.

(21) Guidotti, M.; Pirovano, C.; Ravasio, N.; Lazaro, B.; Fraile, J. M.; Mayoral, J. A.; Coq, B.; Galarneau, A. The use of $\mathrm{H} 2 \mathrm{O} 2$ over titaniumgrafted mesoporous silica catalysts: a step further towards sustainable epoxidation. Green Chem. 2009, 11, 1421-1427.

(22) Greenwood, N. N.; Earnshaw, A. In Chemistry of the Elements; 2nd ed.; Butterworth-Heinemann: Oxford, U.K., 1997; pp 1040-1069.

(23) Gerber, G. B.; Léonard, A.; Hantson, P. Carcinogenicity, mutagenicity and teratogenicity of manganese compounds. Crit. Rev. Oncol. Hematol. 2002, 42, 25-34.

(24) Que, L.; Tolman, W. B. Biologically inspired oxidation catalysis. Nature 2008, 455, 333-340.

(25) Browne, W. R.; De Boer, J. W.; Pijper, D.; Brinksma, J.; Hage, R.; Feringa, B. L. In Modern Oxidation Methods, 2nd ed.; Bäckvall, J.-E., Ed.; Wiley-VCH: Weinheim, Germany, 2010; pp 371-420.

(26) De Vos, D. E.; Sels, B. F.; Jacobs, P. A. Practical heterogeneous catalysts for epoxide production. Adv. Synth. Catal. 2003, 345, 457473.

(27) Qi, B.; Lu, X. H.; Zhou, D.; Xia, Q. H.; Tang, Z. R.; Fang, S. Y.; Pang, T.; Dong, Y. L. Catalytic epoxidation of alkenes with $30 \% \mathrm{H} 2 \mathrm{O} 2$ over Mn2+-exchanged zeolites. J. Mol. Catal. A: Chem. 2010, 322, 7379.

(28) Qi, B.; Lou, L. L.; Wang, Y. B.; Yu, K.; Yang, Y.; Liu, S. X. Comparison of different prepared Mn-MCM-41 catalysts in the catalytic epoxidation of alkenes with $30 \% \mathrm{H} 2 \mathrm{O} 2$. Microporous Mesoporous Mater. 2014, 190, 275-283.

(29) Zheng, W. G.; Tan, R.; Zhao, L. L.; Chen, Y. J.; Xiong, C. W.; Yin, D. H. Mn2+/graphene oxide nanocomposite efficiently catalyzes the epoxidation of alkenes with $\mathrm{H} 2 \mathrm{O} 2$. RSC Adv. 2014, 4, 1173211739.

(30) Escande, V.; Garoux, L.; Grison, C.; Thillier, Y.; Debart, F.; Vasseur, J. J.; Boulanger, C.; Grison, C. Ecological catalysis and phytoextraction: Symbiosis for future. Appl. Catal., B 2014, 146, 279288.

(31) Losfeld, G.; de La Blache, P. V.; Escande, V.; Grison, C. Zinc hyperaccumulating plants as renewable resources for the chlorination process of alcohols. Green Chem. Lett. Rev. 2012, 5, 451-456.

(32) van der Ent, A.; Baker, A. J. M.; Reeves, R. D.; Pollard, A. J.; Schat, H. Hyperaccumulators of metal and metalloid trace elements: Facts and fiction. Plant Soil 2013, 362, 319-334.

(33) Reeves, R. D. In Phytoremediation of Metal-Contaminated Soils; Morel, J.-L., Echevarria, G., Goncharova, N., Eds.; Springer: Amsterdam, The Netherlands, 2006; Vol. 68, pp 25-52.

(34) Bhargava, A.; Carmona, F. F.; Bhargava, M.; Srivastava, S. Approaches for enhanced phytoextraction of heavy metals. J. Environ. Manage. 2012, 105, 103-120.

(35) Grison, C.; Escarré, J. Use of metal-accumulating plants for the preparation of catalysts that can be used in chemical reactions. WO 2011064462 A1 20110603, WO 2011064462 A1 20110603, 2011.

(36) Grison, C.; Escande, V. Use of certain metal-accumulating plants for implementing organic chemistry reactions. WO $2013150197 \mathrm{Al}$ 20131010, 2013.

(37) Grison, C.; Escande, V. Use of certain manganese accumulating plants for the implementation of organic chemistry reactions. FR 2993480 A1 20140124, 2014.

(38) Memon, A. R.; Schroder, P. Implications of metal accumulation mechanisms to phytoremediation. Environ. Sci. Pollut. Res. 2009, 16, $162-175$. 
(39) Fasani, E. In Plants and Heavy Metals; Furini, A., Ed.; Springer: New York, 2012; p 55.

(40) Escande, V.; Olszewski, T. K.; Petit, E.; Grison, C. Biosourced Polymetallic Catalysts: An Efficient Means To Synthesize Underexploited Platform Molecules from Carbohydrates. ChemSusChem 2014, 7, 1915-1923.

(41) Escande, V.; Olszewski, T. K.; Grison, C. Preparation of ecological catalysts derived from $\mathrm{Zn}$ hyperaccumulating plants and their catalytic activity in Diels-Alder reaction. C. R. Chim. 2014, 17, 731-737.

(42) Escande, V.; Velati, A.; Garel, C.; Renard, B.-L.; Petit, E.; Grison, C. Phytoextracted mining wastes for ecocatalysis: Eco-Mn ${ }^{\circledR}$, an efficient and eco-friendly plant-based catalyst for reductive amination of ketones. Green Chem. 2015, 17, 2188-2199.

(43) Lee, D. G.; Chen, T. In Comprehensive Organic Synthesis: Selectivity, Strategy, and Efficiency in Modern Organic Chemistry; Trost, B. M., Fleming, I., Eds.; Pergamon Press: New York, 1991; Vol. 7, pp 541-592.

(44) Farrah, H.; Pickering, W. Extraction of heavy metal ions sorbed on clays. Water, Air, Soil Pollut. 1978, 9, 491-498.

(45) Nesbitt, H. W.; Banerjee, D. Interpretation of XPS Mn(2p) spectra of Mn oxyhydroxides and constraints on the mechanism of $\mathrm{MnO} 2$ precipitation. Am. Mineral. 1998, 83, 305-315.

(46) Grosvenor, A. P.; Kobe, B. A.; Biesinger, M. C.; McIntyre, N. S. Investigation of multiplet splitting of Fe 2p XPS spectra and bonding in iron compounds. Surf. Interface Anal. 2004, 36, 1564-1574.

(47) Feigl, F.; Anger, V. Spot Tests in Inorganic Analysis; 6th English ed.; Elsevier: Amsterdam, The Netherlands, 1972.

(48) Ramanathan, A.; Archipov, T.; Maheswari, R.; Hanefeld, U.; Roduner, E.; Gläser, R. Synthesis, Characterization and Catalytic Properties of the Novel Manganese-Containing Amorphous Mesoporous Material MnTUD-1. J. Phys. Chem. C 2008, 112, 7468-7476.

(49) Qi, B.; Lou, L.-L.; Yu, K.; Bian, W.; Liu, S. Selective epoxidation of alkenes with hydrogen peroxide over efficient and recyclable manganese oxides. Catal. Commun. 2011, 15, 52-55.

(50) Cornélis, A.; Laszlo, P.; Zettler, M. W.; Das, B.; Srinivas, K. V. N. S. In Encyclopedia of Reagents for Organic Synthesis, Montmorillonite K10; John Wiley \& Sons: New York, 2001.

(51) Boldyrev, V. V.; Voronin, A. P.; Nevolina, T. A.; Marusin, V. V. On the question of the existence of $\mathrm{K} 3(\mathrm{MnO} 4) 2$ as an intermediate phase in the thermal decomposition of potassium permanganate. $J$. Solid State Chem. 1977, 20, 327-329.

(52) Herbstein, F. H.; Kapon, M.; Weissman, A. Old and new studies of the thermal decomposition of potassium permanganate. J. Therm. Anal. 1994, 41, 303-322.

(53) Cannon, R. D.; Jayasooriya, U. A.; Tilford, C.; Anson, C. E.; Sowrey, F. E.; Rosseinsky, D. R.; Stride, J. A.; Tasset, F.; Ressouche, E.; White, R. P.; Ballou, R. Electronic Interaction in an Outer-Sphere Mixed-Valence Double Salt: A Polarized Neutron Diffraction Study of K3(MnO4)2. Inorg. Chem. 2004, 43, 7061-7067.

(54) Bakhmutova-Albert, E. V.; Yao, H. R.; Denevan, D. E.; Richardson, D. E. Kinetics and Mechanism of Peroxymonocarbonate Formation. Inorg. Chem. 2010, 49, 11287-11296.

(55) Yao, H. R; Richardson, D. E. Epoxidation of alkenes with bicarbonate-activated hydrogen peroxide. J. Am. Chem. Soc. 2000, 122, $3220-3221$.

(56) Frank, W. C. Surprising stereoselectivity in the Payne epoxidation of terpinen-4-ol with acetonitrile/hydrogen peroxide. Tetrahedron: Asymmetry 1998, 9, 3745-3749.

(57) Lane, B. S.; Burgess, K. A cheap, catalytic, scalable, and environmentally benign method for alkene epoxidations. J. Am. Chem. Soc. 2001, 123, 2933-2934.

(58) Lane, B. S.; Vogt, M.; DeRose, V. J.; Burgess, K. Manganesecatalyzed epoxidations of alkenes in bicarbonate solutions. J. Am. Chem. Soc. 2002, 124, 11946-11954.

(59) Quinonero, D.; Musaev, D. G.; Morokuma, K. Computational insights to the mechanism of alkene epoxidation by manganese-based catalysts in the presence of bicarbonate. J. Mol. Struct.: THEOCHEM 2009, 903, 115-122.
(60) Saisaha, P.; de Boer, J. W.; Browne, W. R. Mechanisms in manganese catalysed oxidation of alkenes with $\mathrm{H} 2 \mathrm{O} 2$. Chem. Soc. Rev. 2013, 42, 2059-2074.

(61) Schaffner, B.; Schaffner, F.; Verevkin, S. P.; Borner, A. Organic Carbonates as Solvents in Synthesis and Catalysis. Chem. Rev. 2010, $110,4554-4581$.

(62) Richardson, D. E.; Yao, H. R.; Frank, K. M.; Bennett, D. A. Equilibria, kinetics, and mechanism in the bicarbonate activation of hydrogen peroxide: Oxidation of sulfides by peroxymonocarbonate. J. Am. Chem. Soc. 2000, 122, 1729-1739.

(63) Kolthoff, I. M.; Becher, R. In Volumetric Analysis; Interscience Publishers: New York, 1957; Vol. 111, pp 75-85.

(64) Sheldon, R. A.; Wallau, M.; Arends, I. W. C. E.; Schuchardt, U. Heterogeneous Catalysts for Liquid-Phase Oxidations: Philosophers' Stones or Trojan Horses? Acc. Chem. Res. 1998, 31, 485-493.

(65) Vigil, M.; Marey-Pérez, M. F.; Martinez Huerta, G.; Álvarez Cabal, V. Is phytoremediation without biomass valorization sustainable? - Comparative LCA of landfilling vs. anaerobic co-digestion. Sci. Total Environ. 2015, 505, 844-850.

(66) Ernst, W. H. O. Phytoextraction of mine wastes - Options and impossibilities. Chem. Erde 2005, 65, 29-42.

(67) van der Ent, A.; Baker, A. J. M.; Reeves, R. D.; Chaney, R. L.; Anderson, C. W. N.; Meech, J. A.; Erskine, P. D.; Simonnot, M.-O.; Vaughan, J.; Morel, J. L.; Echevarria, G.; Fogliani, B.; Rongliang, Q.; Mulligan, D. R. Agromining: Farming for Metals in the Future? Environ. Sci. Technol. 2015, 49, 4773-4780.

(68) Klein, E.; Farnow, H.; Rojahn, W. Die Chemie der Linalooloxide. Justus Liebigs Ann. Chem. 1964, 675, 73-82.

(69) Hirano, M.; Yakabe, S.; Chikamori, H.; Clark, J. H.; Morimoto, T. Oxidation by chemical manganese dioxide. Part 3. Oxidation of benzylic and allylic alcohols, hydroxyarenes and aminoarenes. J. Chem. Res., Synop. 1998, 770-771.

(70) Cahiez, G.; Alami, M.; Taylor, R. J. K.; Reid, M.; Foot, J. S.; Fader, L. Manganese Dioxide. In Encyclopedia of Reagents for Organic Synthesis; John Wiley \& Sons: New York, 2001.

(71) Ohloff, G.; Giersch, W. Conversion of Vicinal Diols into Dicarbonyl-Compounds by Manganese-Dioxide. Angew. Chem., Int. Ed. Engl. 1973, 12, 401-402. 